\title{
Skull X-rays after trauma: are both laterals necessary?
}

A. M. LEAMAN, ${ }^{1}$ D. F. GORMAN, ${ }^{2}$ J. DANHER, ${ }^{3} \&$ T. NIXON ${ }^{3}$ ${ }^{1}$ Royal Liverpool Hospital, ${ }^{2}$ Warrington General Hospital, and ${ }^{3}$ Walton Hospital, Liver $\overrightarrow{0}$ pool, England

\section{SUMMARY}

Eighty-eight sets of skull X-rays, each showing an unequivocal skull fracture, were examined by a radiologist under controlled conditions to see if fractures would be $\overrightarrow{\vec{s}}$ missed if only one lateral view was included in the X-ray series. The fracture sets were mixed at random with four times as many normal sets of skull X-rays and each fracture set was examined on two occasions, once with one lateral and once with both laterals $\overrightarrow{0}$ Two of the fractures were not visible when only one lateral was available.

\section{INTRODUCTION}

Standard textbooks of radiology are unclear as to whether skull X-rays after trauma্ should comprise three views (postero-anterior (PA), Townes and clinically indicatect lateral) or four (PA, Townes, and right and left lateral) (Granger \& Allison, 1986. Sutton, 1980; du Boulay, 1980). With thousands of skull X-ray series being taken eacts year, unnecessary views are an important waste of time and money. The aim of this: study was to see if skull fractures would be missed if only three views of the skull (PA. Townes and clinically indicated lateral) are taken after trauma.

\section{METHOD}

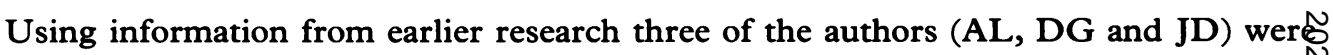
able to collect 88 sets of skull X-rays (PA, Townes and right and left lateral) each o屯 which, in their opinion, showed an unequivocal skull fracture. The patients' ages ranged from 4 months to 89 years and 39 were under 16 years. From the hospital notes 
it was usually possible to identify the clinically indicated lateral. Where this was not possible, the left lateral was assumed to be the clinically indicated lateral for the purposes of this study.

From each set of films, three views (PA, Townes and clinically indicated lateral) were taken and placed in a plain envelope identified only by a number. Three hundred normal skull X-ray series were similarly assembled to provide controls. Fractures were mixed at random with controls in the ratio $1: 4$ and offered to a radiologist (TN) for reporting. The radiologist was unaware of the ratio of fractures to normals and was unaware of the total number of fractures. With each packet a brief clinical history was given and the radiologist was asked: (1) to identify and lateralize the fractures; (2) to state on which views the fracture was visible; and (3) to state which views allowed him to lateralize the fracture.

The whole process was then repeated using four views of both fractures and normals.

\section{RESULTS AND DISCUSSIONS}

The results are summarized in Table 1.

Of the four fractures missed with three views and seen with four views, two were missed because of observer error. That is, these fractures were readily visible on both laterals. Of the remaining two fractures missed, one was visible only on one lateral and this not the clinically indicated lateral (i.e. this fracture was not visible on the PA, Townes or clinically indicated lateral). Because the three views the radiologist was offered were the PA, Townes and clinically indicated lateral, the fracture could not be seen.

The remaining 'fracture' missed with three views and seen with four views was a sphenoid sinus fluid level. On the lateral given in the three views (i.e. the clinically

Table 1 Summary of results

\begin{tabular}{lrc}
\hline Eighty-eight unequivocal skull fractures & $n$ & $(\%)$ \\
\hline Fractures correctly identified with three views and with four views & 74 & $(84)$ \\
Fractures not seen with three views or four views & 7 & $(8)$ \\
Fractures seen with three views but not with four views & 3 & $(3 \cdot 4)$ \\
Fractures seen with four views but not with three views & 4 & $(4 \cdot 5)$ \\
False positive fractures & 3 & \\
Fractures seen only on Townes view & 12 & $(14)$ \\
Fractures seen only on both laterals & 18 & $(20)$ \\
Fractures seen only on one lateral & 2 & $(2 \cdot 3)$ \\
Fractures requiring both laterals to lateralize & 7 & $(8)$ \\
Fractures which could not be lateralized & & $(2 \cdot 3)$ \\
even with both laterals & 2 & \\
$\quad$ Fractures not on clinically indicated side & & \\
$\quad$ where information was available and & & \\
\hline
\end{tabular}


indicated lateral), the fluid level appeared irregular and was deemed a bony edge. On th other lateral, the fluid level appeared much smoother and had moved position. This was much more clearly a fluid level. The PA and Townes view in this series were normalo Thus, both laterals were required to diagnose this basal fracture.

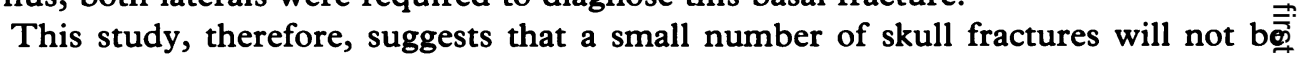
visible if both lateral views are not taken. Because the presence of a fracture is of suct undoubted importance (Jennett, 1980; Mendelow et al., 1983; Gorman, 1985), the् authors believe that both laterals should be taken on each occasion. Others may argue that, where resources are limited, they are better directed towards the much large number of fractures missed because of observer error (vide infra).

The radiologist was given 88 fractures to report on two occasions. Allowing for the two fractures described above, he could be expected to diagnose a fracture on 174 occasions $(88 \times 2-2)$. His actual score was $155(89 \%)$. This is similar to the rate of diagnosis achieved by casualty officers (Gorman, 1987).

Twelve fractures $(14 \%)$ could only be seen on the Townes view. Of these patients nine were children. This suggests that every effort should be made to obtain a Townes: view, particularly in children.

Ten fractures occurred on the side opposite to that clinically indicated. This phenomenon has been reported elsewhere. In a study of 1187 skull fractures in children $28 \%$ had no external evidence of injury and a further $12 \%$ had evidence only on the opposite side to the fracture (Harwood Nash et al., 1971). Similarly, in a port-mortem study of 51 skull fractures, 21 (41\%) had no corresponding external evidence of injur $80^{\circ}$ (Adams et al., 1980). When reporting skull X-rays, radiologists should not place undie reliance on the clinical information given.

In summary, this study suggests that, if skull X-ray series after trauma include on̂t one lateral view, then a small number of fractures may be missed. The importance of tho Townes view, particularly in children, has been emphasized.

\section{REFERENCES}

Adams J. H., Graham D. I., Scott G., Parker L. S. \& Doyle D. (1980) Brain damage in fatal non-missile hea injury. Fournal of Clinical Pathology 33, 1132-45.

du Boulay G. H. (1980) Principles of $X$-ray Diagnosis of the Skull (2nd ed.), p. 359. London: Butterworthso

Gorman D. F. (1985) Were you knocked out? Yes, but I wasn't admitted. Archives of Emergency Medicine 2 , 121-9.

Gorman D. F. (1987) The utility of post-traumatic skull X-rays. Archives of Emergency Medicine 4, 141-5

Granger R. G. \& Allison D. J. (1986) Diagnostic Radiology, Vol. 3, p. 1673. Edinburgh, Churchi Livingstone.

Harwood-Nash D. C., Hendrick E. B. \& Hudson A. R. (1971) The significance of skull fractures in children: study of 1187 patients. Radiology 101, 151-5.

Jennett B. (1980) Skull X-rays after recent head injury. Clinical Radiology 31, 463-9.

Mendelow A. D., Teasdale G., Jennett B., Bryden J., Hessett C. \& Murray G. (1983) Risks of intra-craniw haematoma in head injured adults. British Medical fournal 287, 1173-6.

Sutton D. (1980) Textbook of Radiology and Imaging (3rd ed.), Vol. 2, p. 1075. Edinburgh, Churchif Livingstone. 